Article

\title{
Hydrophilic Titania Thin Films from a Molecular Precursor Film Formed via Electrospray Deposition on a Quartz Glass Substrate Precoated with Carbon Nanotubes
}

\author{
Natangue Heita Shafudah ${ }^{1}$, Hiroki Nagai ${ }^{2}{ }^{\mathbb{D}}$, Yutaka Suwazono $^{1}$, Ryuhei Ozawa $^{3}$, \\ Yukihiro Kudoh ${ }^{3}$ D , Taiju Takahashi ${ }^{3}$, Takeyoshi Onuma ${ }^{2}$ and Mitsunobu Sato ${ }^{1,2, *(D)}$ \\ 1 Applied Chemistry and Chemical Engineering Program, Graduate School of Engineering, \\ Kogakuin University, Tokyo 163-8677, Japan; bd18002@ns.kogakuin.ac.jp (N.H.S.); \\ bd19003@ns.kogakuin.ac.jp (Y.S.) \\ 2 Department of Applied Physics, School of Advanced Engineering, Kogakuin University, Tokyo 163-8677, \\ Japan; nagai@cc.kogakuin.ac.jp (H.N.); onuma@cc.kogakuin.ac.jp (T.O.) \\ 3 Department of Information and Communications Engineering, Faculty of Informatics, Kogakuin University, \\ Tokyo 163-8677, Japan; takeachance.okrock6@gmail.com (R.O.); kudoh@cc.kogakuin.ac.jp (Y.K.); \\ ct12326@ns.kogakuin.ac.jp (T.T.) \\ * Correspondence: lccsato@cc.kogakuin.ac.jp
}

Received: 1 October 2020; Accepted: 26 October 2020; Published: 29 October 2020

\begin{abstract}
Titania precursor films were electrosprayed on a quartz glass substrate, which was pre-modified with an ultra-thin film obtained by spin-coating a single-walled carbon nanotube (SWCNT) dispersed solution. The X-ray diffraction patterns of the thin films obtained by heat-treating the precursor films at $500{ }^{\circ} \mathrm{C}$ in air for $1 \mathrm{~h}$ indicated that the formed crystals were anatase. A new route to fabricate transparent thin films on the insulating substrate via electrospray deposition (ESD) was thus attained. The photoluminescence spectrum of the thin film showed a peak at $2.23 \mathrm{eV}$, assignable to the self-trapped exciton of anatase. The Raman spectrum of the thin film demonstrated that heat treatment is useful for removing SWCNTs. The thin film showed a water contact angle of 14 $\pm 2^{\circ}$ even after being kept under dark conditions for $1 \mathrm{~h}$, indicating a high level of hydrophilicity. Additionally, the thin film had a super-hydrophilic surface with a water contact angle of $1 \pm 1^{\circ}$ after ultraviolet light irradiation with an intensity of $4.5 \mathrm{~mW} \mathrm{~cm} \mathrm{~cm}^{-2}$ at $365 \mathrm{~nm}$ for $1 \mathrm{~h}$. The importance of $\mathrm{Ti}^{3+}$ ions in the co-present amorphous phase, which was dominantly formed via the ESD process, for hydrophilicity was also clarified by means of X-ray photoelectron spectroscopy.
\end{abstract}

Keywords: hydrophilic thin film; titania; electrospray deposition; molecular precursor method

\section{Introduction}

Metal oxide thin films have been widely applied to self-cleaning and anti-fogging of superhydrophilic glasses and mirrors [1,2]. In the case of hydrophilic thin films, several basic approaches have been explored. One approach involves irradiation of photoreactive materials such as titania $\left(\mathrm{TiO}_{2}\right)$ [3], zinc oxide $(\mathrm{ZnO})$ [4], and zirconia $\left(\mathrm{ZrO}_{2}\right)$ [5] (photoinduced superhydrophilicity). However, this phenomenon is caused by light irradiation and loses superhydrophilicity when placed in the dark, resulting in a high-water contact angle of over $50^{\circ}$. Another approach involves the use of a porous surface having a surface texture that promotes hydrophilic behavior [6]. Cebeci et al. prepared a superhydrophilic nanoporous thin film composed of layers of silica nanoparticles [7]. However, the adhesion strength of the porous thin films to the substrate is generally low. 
The electrospray deposition (ESD) process is a simple way to fabricate thin films using high voltage-induced sprays $[8,9]$. By moving the precursor solution through a metallic capillary maintained at high electric potentials, the deposition of spray droplets on the conductive substrate attached to a grounded electrode plate is possible. The stress on the surface of the precursor solution, owing to the established electric field in the solution, promotes the elongation of a jet and its explosion into highly charged droplets. The ESD process, which can be conducted under room temperature and atmospheric pressure conditions, is capable of reducing material loss because droplets fly to the electrode through Coulomb forces.

The molecular precursor method (MPM) developed in our study is a wet chemical process for fabricating metal oxide and phosphate thin films $[10,11]$. The molecular precursor solutions used in the MPM are stable and have many practical advantages in the design of metal complexes in coating solutions with excellent stability, homogeneity, miscibility, and coatability [12]. We have reported the photoinduced superhydrophilization of an O-deficient anatase and rutile thin films, which were obtained by heat-treating the molecular precursor films formed on a quartz glass substrate via the spin-coating process $[13,14]$. The contact angle of $1.0-\mu \mathrm{L}$ water droplets on the O-deficient anatase thin film was $11^{\circ} \pm 3^{\circ}$ and that on the O-deficient rutile thin film was $5^{\circ} \pm 1^{\circ}$. The superhydrophilicity of both thin films was observed by photoinduction with UV light of $4.5 \mathrm{~mW} \mathrm{~cm}^{-2}$ at $365 \mathrm{~nm}$ for $1 \mathrm{~h}$.

In this study, we report a useful procedure to form precursor films for titania on an insulating substrate, such as a quartz glass plate, via the ESD process using a molecular precursor solution. We modified the surface of the insulating quartz glass plate by pre-coating it with a single-walled carbon nanotube (SWCNT) ultra-thin film. The crystal structure and optical properties of the titania thin films obtained by heat-treating the precursor films via an ESD process were compared with those obtained via spin-coating with no pre-modification, along with the properties of the titania thin films formed on a conductive fluorinated tin oxide (FTO) precoated glass substrate under identical conditions. The relationship between the hydrophilic properties and the X-ray photoelectron spectroscopy (XPS) profiles of the obtained titania thin films was also examined.

\section{Materials and Methods}

\subsection{Materials}

A Ti(IV) complex-based molecular precursor solution, TFLEAD, was purchased from FUJIFILM Wako Chemical Corp., Miyazaki, Japan. An SWCNT-dispersed solution (KH OS ET-DOO2), whose SWCNT concentration was 0.05 mass\%, in ethanol was purchased from KH Chemicals Co., Ltd., Gangwon, Korea. Ethanol and 2-propanol (IPA) were purchased from Ueno Chemical Industries, Ltd. Osaka, Japan, and Taisei Chemical Co., Ltd., Tokyo, Japan, respectively. Molecular sieves (3A) were purchased from FUJIFILM Wako Pure Chemical Corp., Osaka, Japan. The polished quartz glass plates with dimensions of $100 \times 100 \times 1.5 \mathrm{~mm}^{3}$ were purchased from Akishima Glass Industry, Tokyo, Japan, and were cut into areal sizes of $20 \times 20 \mathrm{~mm}^{2}$. FTO-precoated glass plates with dimensions of $100 \times 100$ $\times 1.7 \mathrm{~mm}^{3}$ were purchased from AGC Inc., Tokyo, Japan, and were cut in the same areal sizes as the above-mentioned quartz glass plate. These glass substrates were ultra-sonicated in alkaline detergent water, rinsed several times with deionized water, and then kept in IPA. The substrate was dried at 70 ${ }^{\circ} \mathrm{C}$ for $10 \mathrm{~min}$.

\subsection{Preparation of SWCNT Precoated Quartz Glass Substrates}

The original SWCNT-dispersed solution was diluted with ethanol by ultrasonicating for $1 \mathrm{~min}$ to yield a solution with an SWCNT concentration of 0.005 mass $\%$. Next, $300 \mu \mathrm{L}$ of the diluted solution was spin-coated with a double step mode (1st; $500 \mathrm{rpm}-5 \mathrm{~s}$, 2nd; $2000 \mathrm{rpm}-30 \mathrm{~s}$ ) onto the quartz glass substrate. The formed SWCNT ultra-thin film on the quartz glass substrate was oven-dried in air at $70{ }^{\circ} \mathrm{C}$ for $10 \mathrm{~min}$. The SWCNT precoated quartz glass substrate on a single side is denoted as QCNT. 


\subsection{Preparation of Precursor Solutions for ESD and Spin-Coating Processes}

The molecular precursor solution, TFLEAD, whose Ti(IV) concentration was $0.5 \mathrm{mmol} \mathrm{g}^{-1}$, was diluted with IPA to obtain the ESD solution, i.e., $\mathrm{S}_{\mathrm{ESD}}$, with a Ti(IV) concentration of $0.1 \mathrm{mmol} \mathrm{\textrm {g } ^ { - 1 }}$. Next, $10 \mathrm{~g}$ of the $\mathrm{S}_{\mathrm{ESD}}$ was dehydrated on $2 \mathrm{~g}$ of molecular sieves.

The molecular precursor solution, TFLEAD, with a concentration of $0.5 \mathrm{mmol} \mathrm{g}{ }^{-1}$, was diluted with IPA to prepare the precursor solution, $\mathrm{S}_{\mathrm{SPIN}}$, with a Ti(IV) concentration of $0.4 \mathrm{mmol} \mathrm{g}^{-1}$. This diluted solution was used in the spin-coating process without molecular sieve dehydration.

\subsection{Fabrication of the Precursor Film and Titania Thin Film}

The ESD equipment comprised a micro syringe (Hamilton725SNR, Sigma-Aldrich, St. Louis, MO, USA) with a sharpened stainless-steel capillary, a syringe pump (LEGATO 130, Sigma-Aldrich, St. Louis, MO, USA), a grounded aluminum alloy electrode of $14 \mathrm{~cm}$ in diameter, and a DC high-voltage power supply (HJPM-5R0.6, Matsusada, Shiga, Japan). The outer and inner diameters of the 5-cm long stainless steel capillary were $0.72 \mathrm{~mm}$ and $0.15 \mathrm{~mm}$, respectively. The temperature and humidity in the electrospray chamber were maintained in the ranges of $22-26^{\circ} \mathrm{C}$ and $55-65 \%$, respectively. The syringe was vertically set up; the capillary-side was pointed upward. The vertical distance between the capillary tip and substrate attached to the grounded aluminum alloy electrode and the flow rate of the spray solution from the syringe were maintained at $4.0 \mathrm{~cm}$ and $3.0 \mu \mathrm{L} \mathrm{min}^{-1}$, respectively. The precursor films were obtained on three different glass substrates, i.e., the FTO-precoated glass, quartz glass, and QCNT by electrospraying each of them with $120 \mu \mathrm{L}$ of $\mathrm{S}_{\mathrm{ESD}}$ at a voltage of $4.55 \mathrm{kV}$ under identical conditions. Each precursor film obtained via the ESD process on three different substrates was heat-treated in a muffle furnace at $500{ }^{\circ} \mathrm{C}$ in air for $1 \mathrm{~h}$. The heat-treated samples are denoted as FTOESD, QESD, and QCNTESD on the FTO-precoated glass, quartz glass substrate, and QCNT, respectively, as shown in Scheme 1 below.



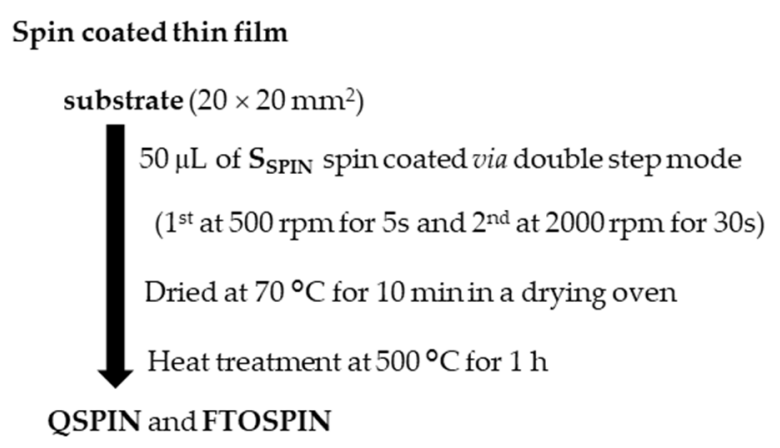

Scheme 1. Flowchart of thin film fabrication.

Next, $50 \mu \mathrm{L}$ of $\mathrm{S}_{\mathrm{SPIN}}$ at room temperature was spin-coated to form the precursor films with a double step mode identical to that for the above-mentioned quartz glass substrate pre-modification. The precursor films were pre-heated in a drying oven at $70{ }^{\circ} \mathrm{C}$ for $10 \mathrm{~min}$. The thin films, FTOSPIN and QSPIN, were obtained by heat-treating the precursor films on the FTO-precoated and quartz glass substrates, respectively, at $500{ }^{\circ} \mathrm{C}$ in air for $1 \mathrm{~h}$, as shown in Scheme 1 above.

Two precursor films denoted as pre-QCNTESD and pre-QSPIN were prepared to measure the transmittance spectra.

\subsection{Characterization of SWCNT Ultra-Thin Film and Titania Thin Films}

\subsubsection{Surface Morphology and Electrical Resistance of SWCNT Ultra-Thin Film}

The surface morphology of the QCNT was observed via atomic force microscopy (AFM) (SFT-4500, SHIMADZU, Kyoto, Japan) by scanning $2 \times 2 \mu \mathrm{m}^{2}$ areas. 
The electrical resistances of the QCNT and FTO-precoated glass substrates were measured using an Inductance Capacitance Resistance (LCR) meter (ANDO AG-4304, Kyoto, Japan) with a four-probe method. The sheet resistance was calculated by multiplying the surface resistance by a constant of 4.24 , according to the distance between each probe of $0.11 \mathrm{~cm}$.

\subsubsection{Surface Morphology, Film Thickness, and Adherent Strength of Titania Thin Films}

The surface morphology of four thin films, FTOESD, FTOSPIN, QCNTESD, and QSPIN, were observed using the aforementioned AFM equipment by scanning each $2 \times 2 \mu \mathrm{m}^{2}$ area. The surface roughness of the thin films was obtained from the three-dimensional (3D) AFM images.

The thickness of the four thin films was measured using a stylus profilometer (DEKTAK-3, Sloan, Sacramento, CA, USA). For the sample preparation, two small portions of each precursor film were removed by ethanol to expose the substrate. The level differences at six positions between the substrate and the resultant thin film were measured for each sample. The film thickness was calculated as an average value.

A stud pull adhesion test was conducted to measure the adhesion strength of two thin films, QCNTESD and QSPIN, onto a quartz glass substrate using a mechanical strength tester (Romulus, Quad Group Inc., Spokane, WA, USA). A stand pin, P/N901106, with an internal diameter of $2.7 \mathrm{~mm}$ was attached to the film with epoxy glue and set in an oven at $150^{\circ} \mathrm{C}$ for $1 \mathrm{~h}$. The test was then performed by pulling the stand pin with a load of $0-100 \mathrm{~kg}$ at a rate of $2.0 \mathrm{~kg} \mathrm{~s}^{-1}$.

\subsubsection{XRD Measurements of Titania Thin Films}

The X-ray diffraction (XRD) patterns of five thin films, FTOESD, FTOSPIN, QESD, QCNTESD, and QSPIN, were measured using an X-ray diffractometer (SMART LAB, Rigaku, Tokyo, Japan) with Cu-K $\alpha$ rays generated at $45 \mathrm{kV}$ and $200 \mathrm{~mA}$. Parallel beam optics with an incident angle of $0.3^{\circ}$ in the $2 \theta$ range of $10-80^{\circ}$, and scanning at a $0.05^{\circ}$ step width and speed of $5^{\circ} \mathrm{min}^{-1}$, were used in each measurement.

The XRD measurement to determine the crystallite size was also performed using the Williamson-Hall (W-H) plot method, in the $2 \theta$ range of $15-60^{\circ}$ scanning at a $0.01^{\circ}$ step width and a fixed time of $5 \mathrm{~s}$ in each step. The crystallite sizes of the anatase crystals in four thin films, FTOESD, FTOSPIN, QCNTESD, and QSPIN, were calculated using the data of the (101) phase, according to Equation (1) [15], where $D, \beta, \lambda, \varepsilon$, and $\theta$ represent the crystallite size, full width at half maximum (FWHM) of the diffraction peak, wavelength of X-ray, lattice strain, and Bragg angle, respectively, of the (101) anatase phase. A $K$ value of 0.9 was used as the Scherrer constant.

$$
\beta \cos \theta=\frac{K \lambda}{D}+4 \varepsilon \sin \theta
$$

The crystallite size of anatase in these films was determined from the y-intercept of the linear fitting gradient by the $\mathrm{W}-\mathrm{H}$ plot.

\subsubsection{Chemical Characterization of Titania Thin Films}

The XPS measurements for four thin films, FTOESD, FTOSPIN, QCNTESD, and QSPIN, were performed using a photoelectron spectrometer (JPS-9030, JEOL Ltd., Tokyo, Japan), with Al-K $\alpha$ radiation at a $1486.6 \mathrm{eV}$ source in the range of $100-900 \mathrm{eV}$. The thin films were etched for $3 \mathrm{~min}$ using $\mathrm{Ar}^{+}$ion beam bombardment at a voltage of $300 \mathrm{~V}$ and current of $3.5 \mathrm{~mA}$ for the removal of surface contamination before measurement. The $\mathrm{C}-\mathrm{C}$ peak at $285 \mathrm{eV}$ was used as a reference for binding energy calibration, and the resolution was $0.1 \mathrm{eV}$ in each measurement.

The XPS peaks derived from $\mathrm{O}$ and $\mathrm{Ti}$ atoms in the four thin films were quantitatively analyzed using OriginPro2018b (OriginLab Corporation, MA, USA). After the binding energy correction and Shirley-type background correction, the position and FWHM of each peak were then refined. The Ti $2 p$ peaks were deconvoluted into eight peaks by a nonlinear least-square method with the use of the Voigt 
function, according to our recent work [16]. The peak fitting converged with a $\chi^{2}$ tolerance value of 1 $\times 10^{-9}$, indicating that the difference between experimental and theoretical data is sufficiently small.

The $\mathrm{O} / \mathrm{Ti}$ ratio of the four thin films was evaluated from the peak areas of $\mathrm{O} 1 \mathrm{~s}$ and the deconvoluted $\operatorname{Ti} 2 p_{3 / 2}$ peaks, and the corresponding relative sensitivity factors were obtained using the SpecSurf software (JEOL Ltd., Tokyo, Japan), according to the following Equation (2):

$$
\mathrm{O} / \text { Ti ratio }=\frac{\frac{\text { peak area of } \mathrm{O} 1 \mathrm{~s}}{\text { relative sensitivity factor of } \mathrm{O} 1 \mathrm{~s}}}{\frac{\text { peak area of } \mathrm{Ti} 2 \mathrm{p}_{3 / 2}}{\text { relative sensitivity factor of } \mathrm{Ti} 2 \mathrm{p}_{3 / 2}}}
$$

\subsubsection{Raman Spectra of SWCNT Ultra-Thin Film and Titania Thin Films}

The Raman spectra of the QCNT and four thin films, FTOESD, FTOSPIN, QCNTESD, and QSPIN, were measured using a Raman microspectrometer (LaBRAM HR800, Horiba Ltd., Kyoto, Japan) with a charge-coupled device detector. An Nd: YAG laser (532 nm) was used as the excitation source, with an intensity of $13 \mathrm{~mW}$ and exposure time of $180 \mathrm{~s}$. The spectra were measured in back-scattering geometry, and the spot diameter of the laser light was $1 \mu \mathrm{m}$. The spectrometer was set to $950 \mathrm{~cm}^{-1}$ to yield each spectrum in the wavenumber range from 54 to $1759 \mathrm{~cm}^{-1}$, obtained by exposing the laser beam for $30 \mathrm{~min}$ on the sample thin film. Before the thin film measurements, a silicon reference sample with a Raman peak at $520.64 \mathrm{~cm}^{-1}$ was used for the calibration of the instrument.

\subsubsection{Transmittance Spectra of Titania Thin Films and Precursor Films on Quartz Glass Substrate}

The transmittance spectra of the thin films, QCNTESD and QSPIN, on the quartz glass substrate were measured in the range of 200-1100 nm using a double beam spectrophotometer (U-2800, Hitachi, Tokyo, Japan). The transmittance spectra of the precursor films, pre-QCNTESD and pre-QSPIN, before heat treatment were also measured identically to those of the heat-treated thin films. A quartz glass substrate was used as a reference for the measurements.

The Tauc plot obtained using the transmittance data was used to estimate the optical bandgap of the thin films, QCNTESD and QSPIN, using the expressions of $E$ versus $(h v \alpha)^{1 / n}$, where $E, h, v, \alpha$, and $n$ represented photon energy, Planck's constant, wavenumber, absorption coefficient, and integer depending on the type of transition ( $n=2$, assumption of indirect bandgap) [17]. The absorption coefficient $\alpha$ can be defined according to Equation (3), using the film thickness $(d)$ and transmittance $(T)$.

$$
\alpha=\frac{1}{d} \ln \left(\frac{1}{T}\right)
$$

\subsubsection{Refractive Index of Titania Thin Films on Quartz Glass Substrate}

A scanning ellipsometer (MARY-102, Five Lab, Saitama, Japan) was employed to measure the refractive index of four titania thin films with a He-Ne laser beam of $632.8 \mathrm{~nm}$ and an incident angle of $70.8^{\circ}$. To calibrate the measured data, bulk anatase with a refractive index of 2.52 was used [18]. For QCNTESD and QSPIN, a refractive index of 1.54 for the quartz glass substrate was used based on the literature value [19]. The refractive index was measured at five different points on the thin films, and the average value was calculated as each refractive index.

\subsubsection{Photoluminescence Spectra of Titania Thin Films on Quartz Glass Substrate}

The photoluminescence (PL) spectra of the QCNTESD and QSPIN were measured in the energy range of $1.46-3.66 \mathrm{eV}$, corresponding to a wavelength of $847-339 \mathrm{~nm}$, at room temperature using a CW He-Cd laser (Kimmon He-Cd, KIMMON KOHA, Tokyo, Japan) whose emitting wavelength was $325.0 \mathrm{~nm}$ with an excitation power of $33 \mathrm{~mW}$. The laser was dispersed by means of a Czerny-Turner monochromator (HR-640, Jobin Yvon, Edison, NJ, USA) equipped with a 600 grooves $\mathrm{mm}^{-1}$ grating, and 
the dispersed light was detected by a photomultiplier tube (R1104, Hamamatsu Photonics, Shizuoka, Japan) using the lock-in detection technique.

\subsection{Hydrophilicity of Titania Thin Films}

The contact angles of a $1.0 \mu \mathrm{L}$ water droplet on each surface of four thin films, FTOESD, FTOSPIN, QCNTESD, and QSPIN, were obtained by means of a contact angle meter (FACE, Kyowa Interface Science, Saitama, Japan). Before the measurement, the thin film samples were kept in the dark for $1 \mathrm{~h}$. The contact angles were measured at $26^{\circ} \mathrm{C}$ and $50 \%$ humidity. Then, ultraviolet (UV) light, whose intensity was monitored with a UV meter (UVR-400, Iuchi, Tokyo, Japan) as $4.5 \mathrm{~mW} \mathrm{~cm}{ }^{-2}$ at $365 \mathrm{~nm}$, was irradiated for $1 \mathrm{~h}$ onto each sample surface, using a black light (FL10BL-B, Toshiba, Tokyo, Japan). The contact angles of the UV-irradiated samples were measured at the above-mentioned temperature and humidity.

\section{Results}

\subsection{Surface Morphology and Sheet Resistance of QCNT}

In Figure 1, the 2D and 3D-AFM images of the QCNT are presented. Intertwined networks of linear-like SWCNT molecules and several round-shaped particles with diameters of approximately $0.2 \mu \mathrm{m}$ can be observed. The sheet resistance of the QCNT was $2.0 \times 10^{6} \Omega / \mathrm{sq}$, as determined by the LCR meter.

(a)

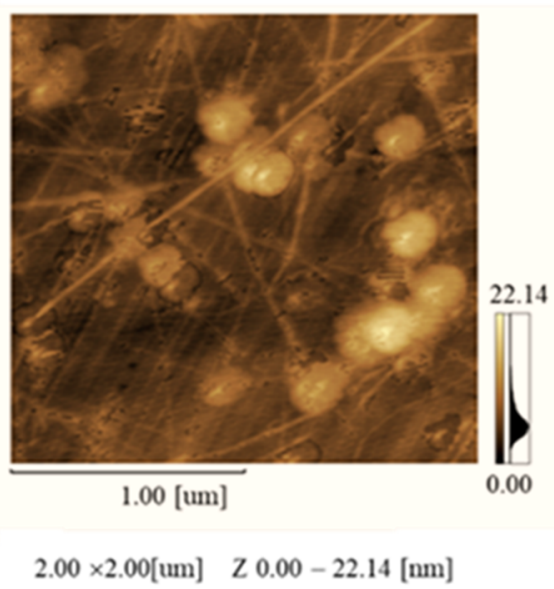

(b)

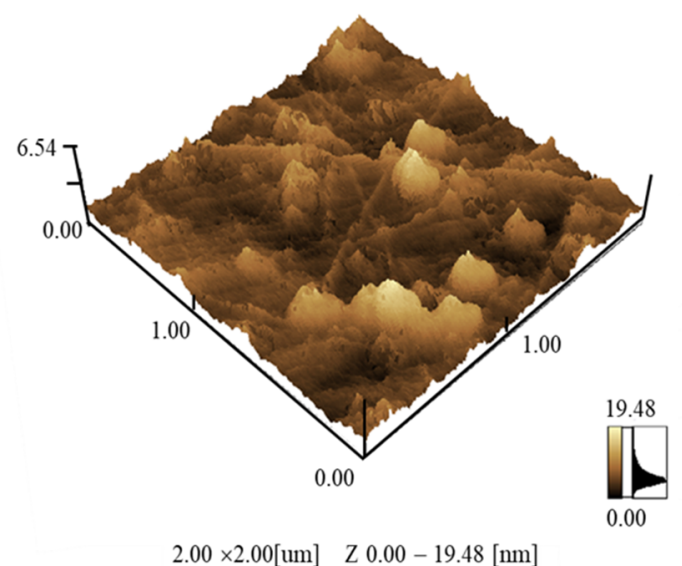

Figure 1. (a) 2D- and (b) 3D-AFM images of the SWCNT pre-coated quartz glass substrate, QCNT.

\subsection{Surface Morphology, Film Thickness, and Adhesion Strength of Titania Thin Films}

Figure 2 shows the 3D-AFM images of four thin films, FTOESD, FTOSPIN, QCNTESD, and QSPIN. The observed surfaces of FTOESD and FTOSPIN are rough (Figure 2a,b). However, QCNTESD and QSPIN have quite smooth surfaces (Figure 2c,d).

The surface roughness and film thickness of the four thin films are listed in Table 1. The film thickness of the FTOESD and QCNTESD via the ESD process for forming the precursor film is $10 \mathrm{~nm}$ thinner than that of FTOSPIN and QSPIN via spin-coating. The film thickness of the QESD could not be determined because no level difference between the thin film and substrate could be found. 
(a)

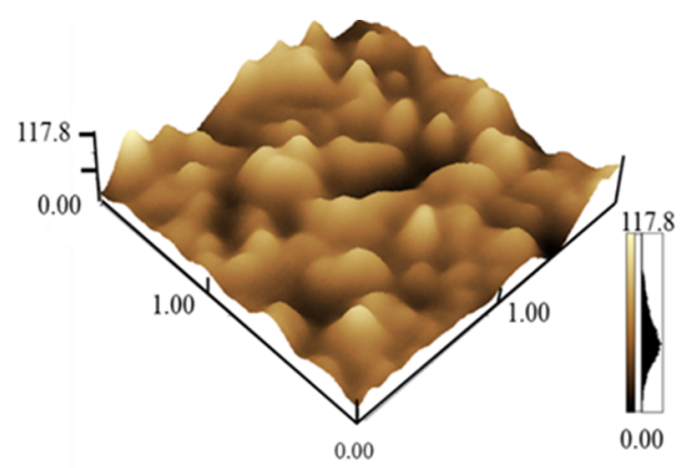

$2 \times 2[\mathrm{um}] \mathrm{Z} 0.00-117.8[\mathrm{~nm}]$

(c)

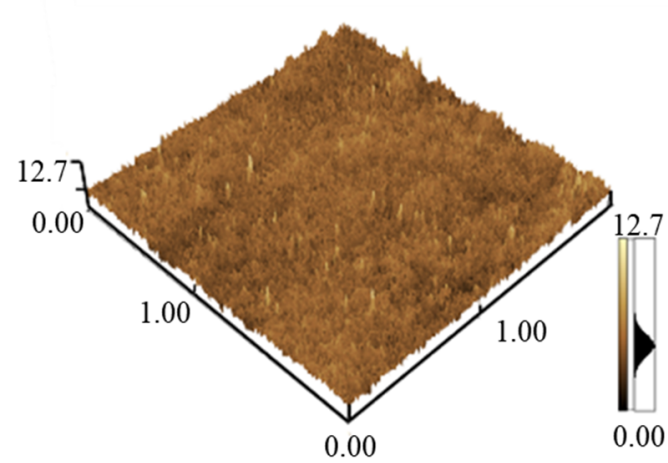

$2 \times 2[\mathrm{um}] \mathrm{Z} 0.00-12.7[\mathrm{~nm}]$ (b)

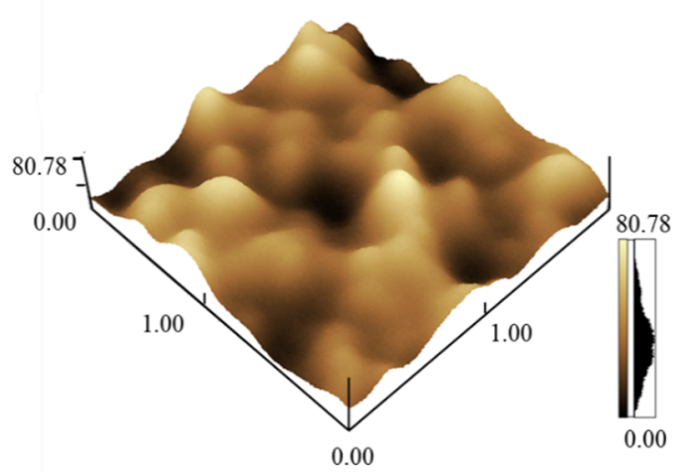

$2 \times 2[\mathrm{um}] \mathrm{Z} 0.00-80.78[\mathrm{~nm}]$

(d)

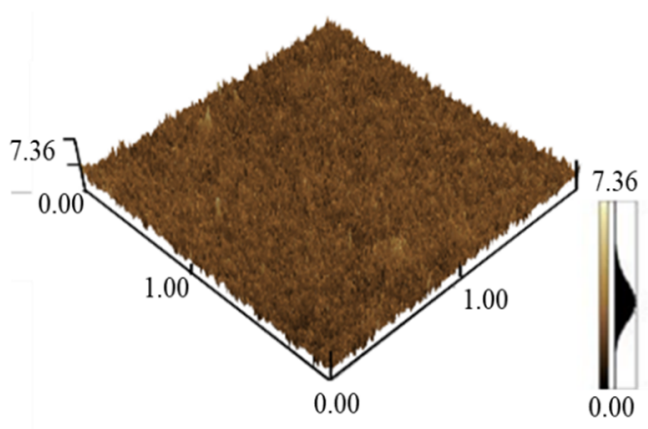

$2.00 \times 2.00[\mathrm{um}] \quad \mathrm{Z} 0.00-7.36[\mathrm{~nm}]$

Figure 2. Three-dimensional-AFM images of the heat-treated films on two different glass substrates fabricated via the ESD and spin-coating processes: (a) FTOESD; (b) FTOSPIN; (c) QCNTESD; (d) QSPIN.

Table 1. Surface roughness and film thickness of the heat-treated thin films on two different glass substrates prepared via the ESD and spin-coating processes, FTOESD, FTOSPIN, QCNTESD, and QSPIN.

\begin{tabular}{ccc}
\hline Thin Films & Surface Roughness/nm & Film Thickness/nm \\
\hline FTOESD & 15.5 & 90 \\
FTOSPIN & 12.3 & 100 \\
QCNTESD & 1.0 & 90 \\
QSPIN & 0.7 & 100 \\
\hline
\end{tabular}

The adhesion strengths of the QCNTESD and QSPIN are 65.3(9) MPa and 64.1(6) MPa, respectively, whereby the standard deviations are presented in parentheses.

\subsection{XRD Patterns of Titania Thin Films}

Figure 3 shows the XRD patterns of five thin films, FTOESD, FTOSPIN, QESD, QCNTESD, and QSPIN, from $10^{\circ}$ to $70^{\circ}$. 
(a)

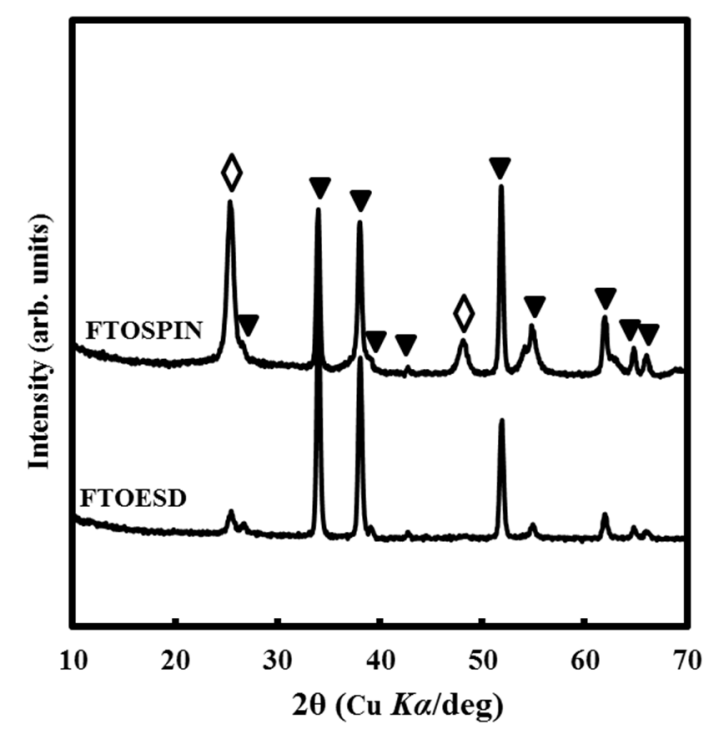

(b)

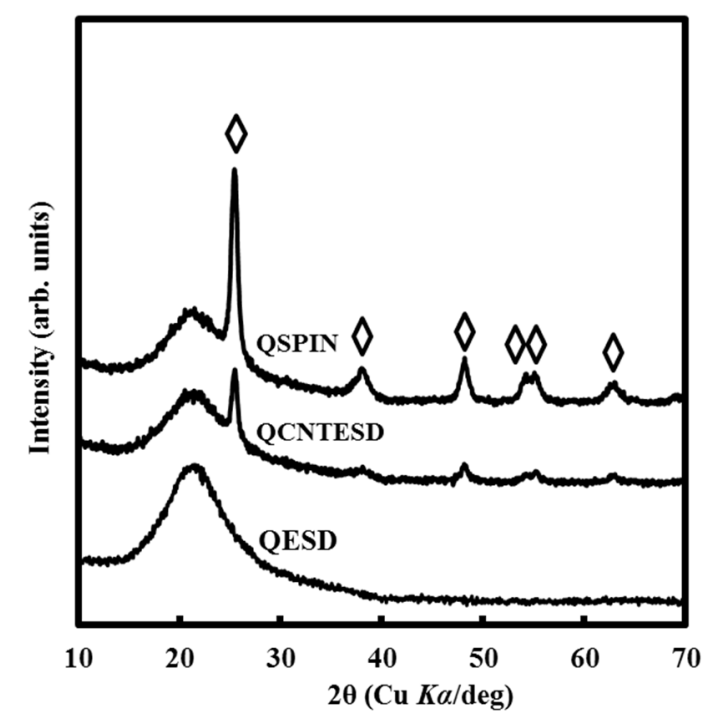

Figure 3. XRD patterns of the resultant thin films; (a) FTOESD and FTOSPIN; (b) QESD, QCNTESD, and QSPIN. The peak assignment is denoted as follows; $\diamond$ anatase, $\nabla \mathrm{SnO}_{2}$ in the FTO-precoated glass substrate.

The two weak peaks at $2 \theta=25.4^{\circ}$ and $48.2^{\circ}$ can be observed in the case of the FTOESD and FTOSPIN (Figure 3a), and they are assigned to the (101) and (200) phases of anatase, respectively [20]. The additional twelve peaks of the FTOESD and FTOSPIN can be assigned to those of $\mathrm{SnO}_{2}$ of the FTO-precoated glass substrate [21].

The six peaks at $2 \theta=25.4^{\circ}, 38.1^{\circ}, 48.2^{\circ}, 54.3^{\circ}, 55.3^{\circ}$, and $63.1^{\circ}$ could be observed for QCNTESD and QSPIN, and they were ascribed to the (101), (004), (200), (105), (211), and (204) phases of anatase, respectively, although no clear peak was observed in the case of QESD.

Table 2 shows the crystallite sizes of the four thin films, along with their standard deviations. The crystallite sizes of the thin films were almost identical to each other.

Table 2. Crystallite size of the anatase crystals in the heat-treated thin films on two different glass substrates prepared via the ESD and spin-coating processes, FTOESD, FTOSPIN, QCNTESD, and QSPIN.

\begin{tabular}{cc}
\hline Thin Film & Crystallite Size $^{(\mathbf{a}) / \mathbf{n m}}$ \\
\hline FTOESD & $11.3(4)$ \\
FTOSPIN & $11.7(4)$ \\
QCNTESD & $12(1)$ \\
QSPIN & $11.7(3)$ \\
\hline
\end{tabular}

(a) The standard deviations are presented in parentheses.

\subsection{Chemical Characterization of Titania Thin Films}

Figure 4 shows the wide-range XPS profiles of the four thin films, FTOESD, FTOSPIN, QCNTESD, and QSPIN.

Peaks assignable to Ti $2 \mathrm{p}$ and $\mathrm{O} 1$ s orbital electrons can be observed at binding energies in the range of 452-468 eV and at approximately $531 \mathrm{eV}$, respectively, in all the thin films. Very small peaks assignable to carbon and nitrogen atoms can also be observed in the spectra of all the thin films. 
(a)

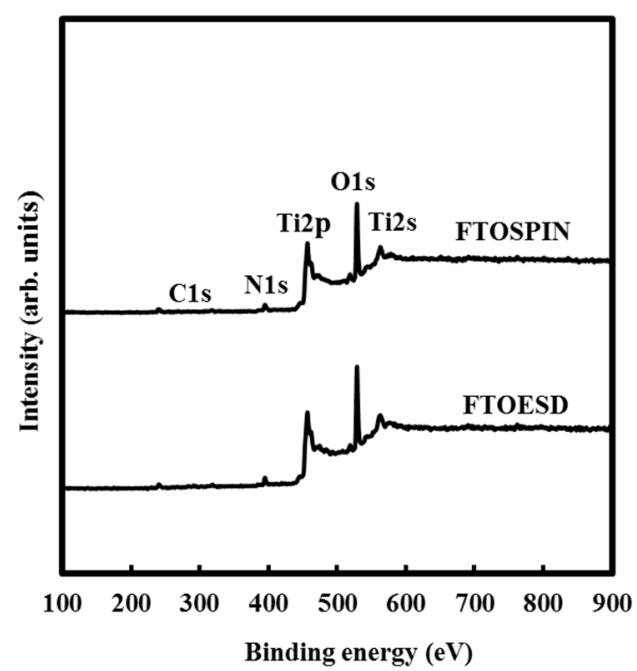

(b)

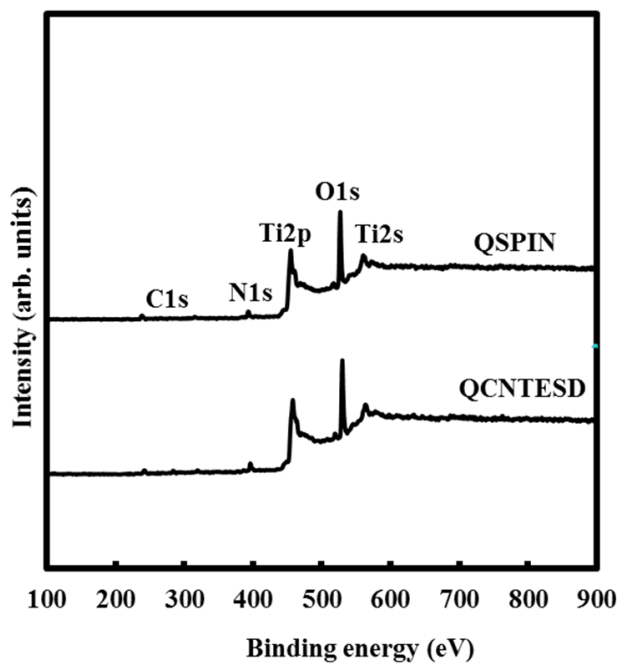

Figure 4. Wide-range XPS profiles of the titania thin films: (a) FTOESD and FTOSPIN; (b) QCNTESD and QSPIN.

The broad bands of the binding energies derived from Ti $2 \mathrm{p}$ orbital electrons could be deconvoluted into eight peaks owing to the $\mathrm{Ti}^{0}, \mathrm{Ti}^{2+}, \mathrm{Ti}^{3+}$, and $\mathrm{Ti}^{4+}$ species, respectively. The peaks due to the $\mathrm{O} 1 \mathrm{~s}$ electrons were well fitted to each Voigt curve. The deconvolution results for the broad peaks due to $\mathrm{Ti}$ 2 p electrons are presented in Figure 5, along with each corresponding XPS band observed for the four thin films, in the energy range of Ti $2 p$ electrons.

In Table 3 , the binding energies of the $\mathrm{Ti} 2 \mathrm{p}_{3 / 2}$ and $\mathrm{Ti} 2 \mathrm{p}_{1 / 2}$ electrons belonging to the $\mathrm{Ti}^{0}, \mathrm{Ti}^{2+}, \mathrm{Ti}^{3+}$, and $\mathrm{Ti}^{4+}$ species, as well as the percentage of each ion in the whole Ti atom are summarized, along with the $\mathrm{O} / \mathrm{Ti}$ ratio.

Table 3. Binding energies obtained by deconvolution of XPS peaks assignable to Ti $2 p$ electrons, percentages of the $\mathrm{Ti}^{0}, \mathrm{Ti}^{2+}, \mathrm{Ti}^{3+}$, and $\mathrm{Ti}^{4+}$ species in total $\mathrm{Ti}$ atom, and $\mathrm{O} / \mathrm{Ti}$ ratios of the heat-treated thin films on two different glass substrates prepared via the ESD and spin-coating processes, FTOESD, FTOSPIN, QCNTESD, and QSPIN.

\begin{tabular}{|c|c|c|c|c|c|c|c|c|c|}
\hline \multirow{3}{*}{$\begin{array}{l}\text { Charge of Ti Atom } \\
\text { Assigned Electrons } \\
\text { Binding Energy/eV }\end{array}$} & \multicolumn{2}{|c|}{0} & \multicolumn{2}{|c|}{+2} & \multicolumn{2}{|c|}{+3} & \multicolumn{2}{|c|}{+4} & \multirow[t]{3}{*}{$\mathrm{O} / \mathrm{Ti}$} \\
\hline & $2 \mathrm{p}_{3 / 2}$ & $2 \mathrm{p}_{1 / 2}$ & $2 \mathrm{p}_{3 / 2}$ & $2 \mathrm{p}_{1 / 2}$ & $2 \mathrm{p}_{3 / 2}$ & $2 \mathrm{p}_{1 / 2}$ & $2 \mathrm{p}_{3 / 2}$ & $2 \mathrm{p}_{1 / 2}$ & \\
\hline & 453.5 & 459.7 & 455.3 & 460.8 & 456.9 & 462.0 & 458.8 & 464.2 & \\
\hline FTOESD & \multicolumn{2}{|c|}{1.0} & \multicolumn{2}{|c|}{19.1} & 25.3 & & 54.5 & & 1.81 \\
\hline FTOSPIN & \multicolumn{2}{|c|}{1.4} & \multicolumn{2}{|c|}{21.0} & 28.4 & & 49.2 & & 1.81 \\
\hline QCNTESD & \multicolumn{2}{|c|}{1.0} & \multicolumn{2}{|c|}{20.0} & 28.0 & & 51.0 & & 1.77 \\
\hline QSPIN & \multicolumn{2}{|c|}{0.7} & \multicolumn{2}{|c|}{17.0} & 32.0 & & 51.0 & & 1.72 \\
\hline
\end{tabular}

The binding energies assigned to the $\mathrm{Ti} 2 \mathrm{p}_{3 / 2}$ and $\mathrm{Ti} 2 \mathrm{p}_{1 / 2}$ electrons belonging to each $\mathrm{Ti}$ atom are comparable to those reported previously [20]. The energy differences of 5.1-6.2 eV between the Ti $2 \mathrm{p}_{3 / 2}$ and $\mathrm{Ti} 2 \mathrm{p}_{1 / 2}$ peaks are also agreeable with the doublet separation of the Ti species. The O/Ti ratios are distributed from 1.72 for the QSPIN to 1.81 for FTOESD and FTOSPIN. None of the parameters obtained by these XPS analyses are significantly different between the thin films via the ESD and spin-coating processes. 
(a)

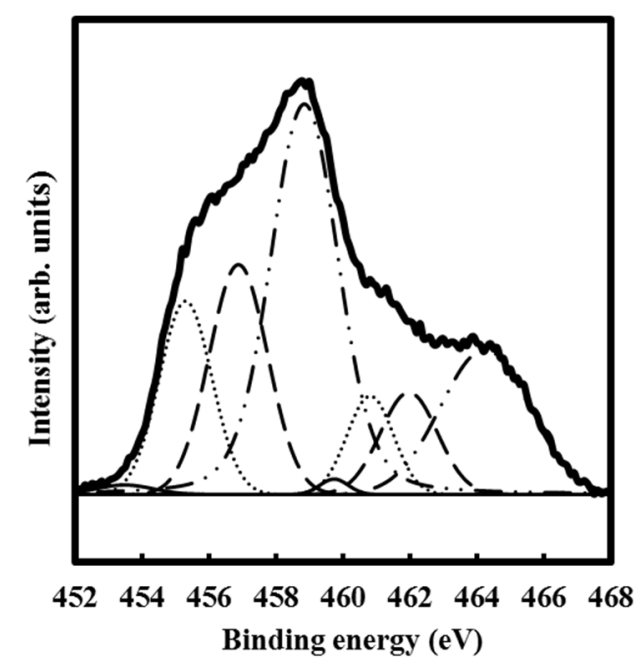

(c)

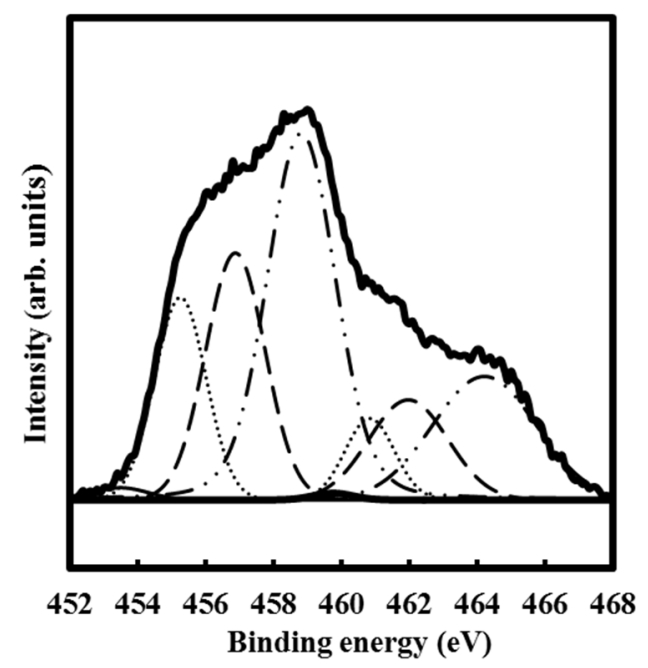

(b)

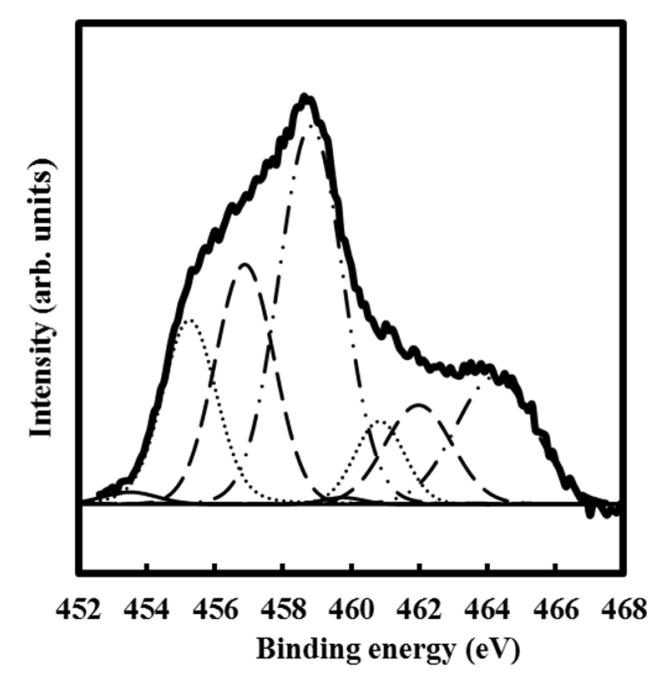

(d)

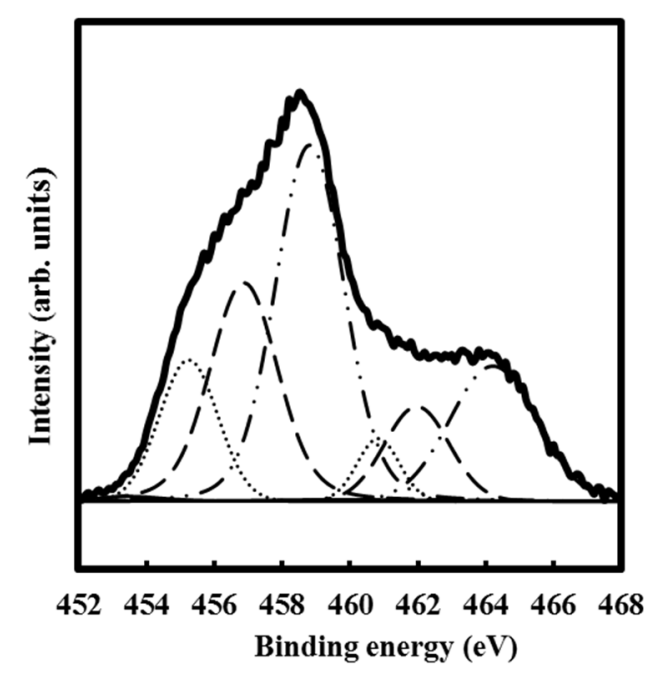

Figure 5. Deconvoluted Ti 2p peaks in XPS profiles of the Titania thin films: (a) FTOESD; (b) FTOSPIN; (c) QCNTESD; (d) QSPIN. The thick line (-) indicates the original XPS band corresponding to the binding energy range of Ti $2 p$ electrons, while the lines, $(-),(\ldots),(-)$, and (-..-) indicate the theoretically fitted curves assuming the Voigt distribution for $\mathrm{Ti}^{0}, \mathrm{Ti}^{2+}, \mathrm{Ti}^{3+}$, and $\mathrm{Ti}^{4+}$ species, respectively.

\subsection{Raman Spectra of SWCNT Ultra-Thin Film and Titania Thin Films}

The Raman spectra of the SWCNT ultrathin film, QCNT, and four thin films, FTOESD, FTOSPIN, QCNTESD, and QSPIN, from 100 to $700 \mathrm{~cm}^{-1}$ are presented in Figure 6, along with those of the FTO-precoated and quartz glass substrates. 
(a)

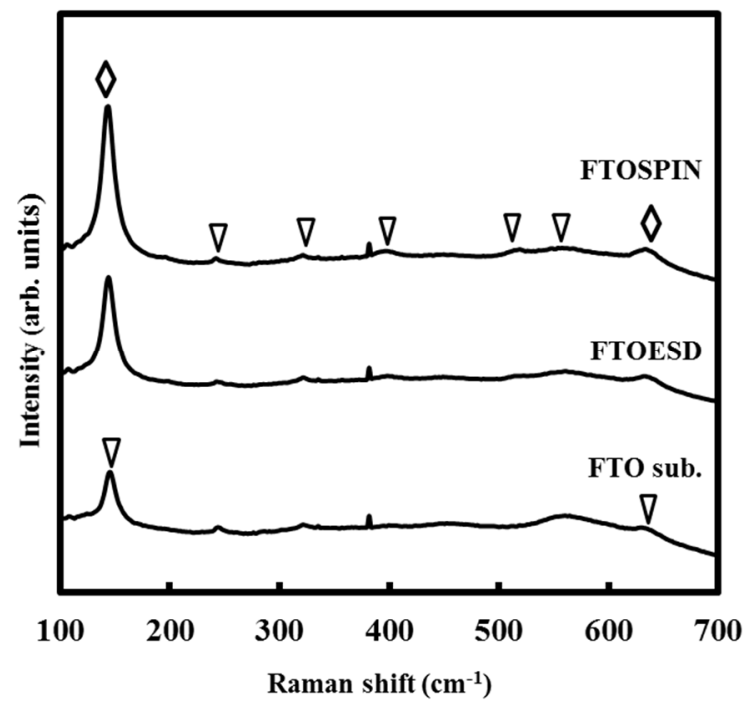

(b)



Figure 6. Raman spectra of the titania thin films on two different substrates, along with that of each substrate: (a) FTO-precoated glass substrate, FTOESD, and FTOSPIN, where the symbols represent anatase $(\diamond)$ and FTO (.); (b) quartz glass substrate, QCNT, QCNTESD, and QSPIN, where the symbols represent anatase $(\diamond)$, Radial breathing mode $(\mathrm{RBM})(\diamond)$ of SWCNT, and quartz glass substrate $(\mid)$.

The peaks at 144 and $634 \mathrm{~cm}^{-1}$ observed for FTOESD and FTOSPIN are assignable to the $E_{\mathrm{g}}$ phononic mode of anatase [21]. The other peaks are consistent with those of the FTO-precoated glass substrate.

In the case of QCNTs, three peaks at 174,189 , and $198 \mathrm{~cm}^{-1}$ can be observed and are assignable to the radial breathing mode (RBM) of the SWCNT structure [22]. The peaks detected at 140 and 635 $\mathrm{cm}^{-1}$ in each pattern of the QCNTESD and QSPIN can also be ascribed to the $E_{\mathrm{g}}$ phononic mode of anatase, while the other peaks are consistent with those of the quartz glass substrate.

\subsection{Optical Properties of Titania Thin Films and Precursor Films on Quartz Glass Substrate}

Figure 7a shows the UV-Vis transmittance spectra of QCNTESD and QSPIN. Transmittance of over $80 \%$ can be observed in the visible and near infrared regions of both thin films. In addition, the transmittance of the QCNTESD is 5\% in the UV region, although that of the QSPIN is $0 \%$ in the wavelength region shorter than $280 \mathrm{~nm}$.

Figure $7 \mathrm{~b}$ shows those of the corresponding precursor films, pre-QCNTESD and pre-QSPIN. The transmittance spectrum of pre-QCNTESD is blue-shifted by a maximum value of $40 \mathrm{~nm}$ from that of pre-QSPIN in the UV region.

Figure $7 \mathrm{c}$ shows the Tauc plots obtained from the transmittance spectra of the QCNTESD and QSPIN.

Table 4 summarizes the refractive index and bandgap of the QCNTESD and QSPIN. The refractive index of the QCNTESD via the ESD process is 0.33 lower than that of the QSPIN, while the optical bandgap of the QCNTESD is $0.04 \mathrm{eV}$ lower than that of the QSPIN. 
(a)

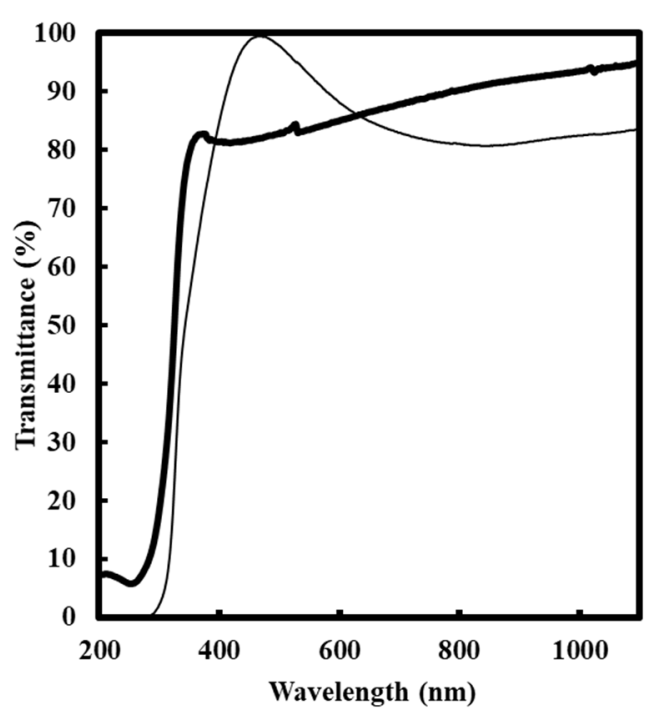

(b)

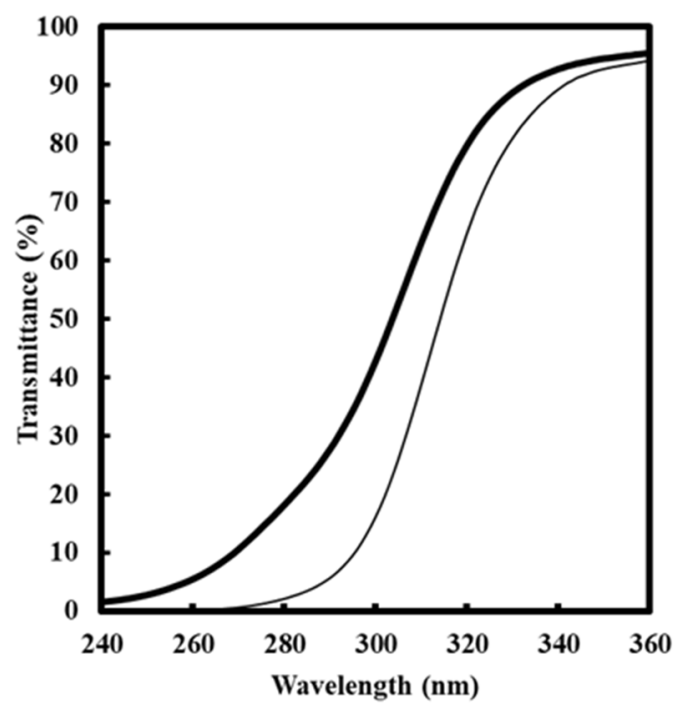

(c)

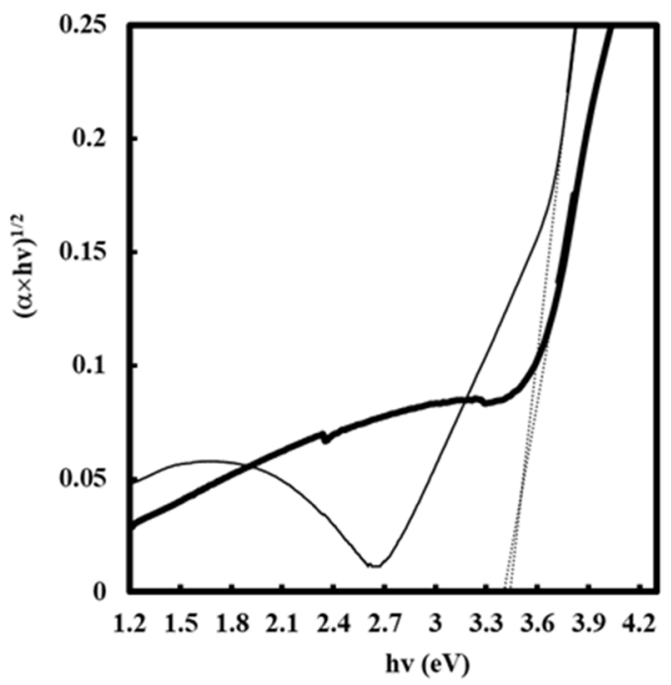

Figure 7. Transmittance spectra of the titania thin films: (a) QCNTESD and QSPIN, and the corresponding precursor films; (b) pre-QCNTESD and pre-QSPIN, along with the Tauc plots ( ... ) of the titania thin films; (c) QCNTESD and QSPIN. The lines represent the spectra of thin films prepared via the ESD (-) and spin-coating processes (-).

Table 4. Refractive index and optical bandgap of the heat-treated thin films on the quartz glass substrate prepared via the ESD and spin-coating processes, QCNTESD and QSPIN. The bandgap was obtained based on the assumption of the indirect transition.

\begin{tabular}{ccc}
\hline Thin Films & Refractive Index & Bandgap/eV \\
\hline QCNTESD & 1.81 & 3.40 \\
QSPIN & 2.14 & 3.44 \\
\hline
\end{tabular}

\subsection{Photoluminescence Spectra of Titania Thin Films on Quartz Glass Substrate}

The PL spectra of the QCNTESD and QSPIN are shown in Figure 8. The highest peak positions of the QCNTESD and QSPIN are found at approximately $2.23 \mathrm{eV}$ and $2.50 \mathrm{eV}$, respectively. The energy 
values of the observed PL emissions are centered at $2.23 \mathrm{eV}$ and $2.50 \mathrm{eV}$ with broad emission (FWHM: $0.8-0.9 \mathrm{eV}$ ) as the self-trapped exciton by anatase $[23,24]$. The low energy value of the observed PL emissions centered near $1.6 \mathrm{eV}$ could be assignable to $\mathrm{Ti}^{3+}$ interstitial ion and the associated defect levels $[25,26]$.

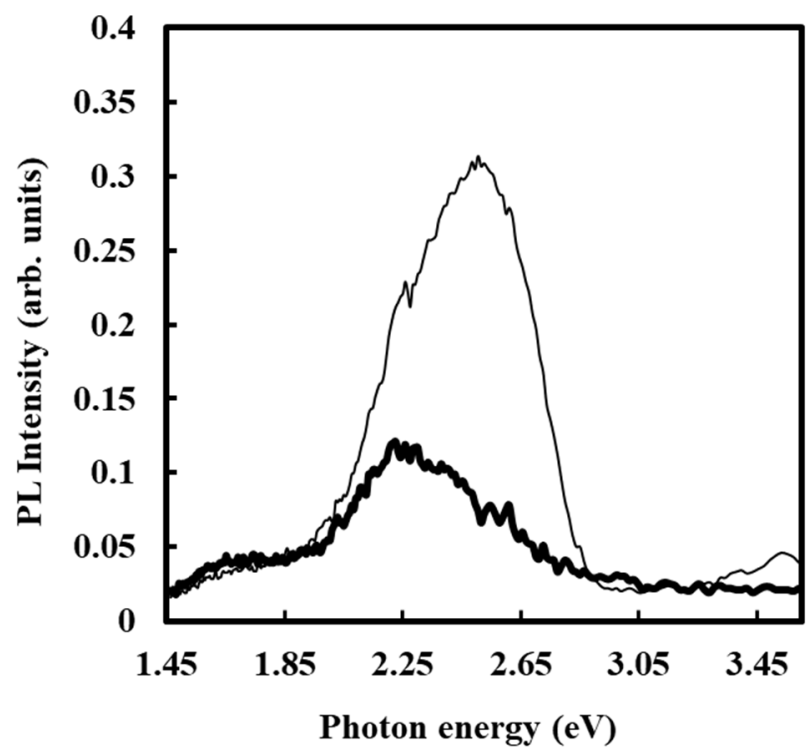

Figure 8. Photoluminescence spectra of the titania thin films on the quartz glass substrate. The lines represent the QCNTESD (-) and QSPIN (-).

\subsection{Hydrophilicity of Thin Films}

In Table 5, the water contact angles of the $1.0 \mu \mathrm{L}$ water droplet on the surface of four thin films, FTOESD, FTOSPIN, QCNTESD, and QSPIN, before and after UV light irradiation are summarized.

Table 5. Water contact angle of $1.0 \mu \mathrm{L}$ water droplet on the surface of the heat-treated thin films on two different glass substrates prepared via the ESD and spin-coating processes, FTOESD, FTOSPIN, QCNTESD, and QSPIN, before and after UV-light irradiation with an intensity of $4.5 \mathrm{~mW} \mathrm{~cm}^{-2}$ at $365 \mathrm{~nm}$ for $1 \mathrm{~h}$. Those before UV irradiation were measured after the samples were kept under dark conditions for $1 \mathrm{~h}$.

\begin{tabular}{|c|c|c|}
\hline Thin Films & Before UV Irradiation & After UV Irradiation \\
\hline FTOESD & $15 \pm 1^{\circ}$ & $0^{\circ}$ \\
\hline FTOSPIN & $54 \pm 5^{\circ}$ & $14 \pm 1^{\circ}$ \\
\hline QCNTESD & $14 \pm 2^{\circ}$ & $1 \pm 1^{\circ}$ \\
\hline QSPIN & $60 \pm 3^{\circ}$ & $12 \pm 1^{\circ}$ \\
\hline
\end{tabular}

The water contact angles of the two thin films fabricated via the ESD process are less than $15^{\circ}$, even after being kept in the dark for $1 \mathrm{~h}$. Conversely, for those of two thin films fabricated via the 
spin-coating process, the corresponding angles exceed $50^{\circ}$. The water contact angle of all the thin films decreased after UV irradiation, thereby demonstrating photo-induced hydrophilicity. Among them, two thin films, FTOESD and QCNTESD, have super-hydrophilic surfaces with water contact angles of less than $1^{\circ}$.

\section{Discussion}

\subsection{Fabrication of Titania Thin Films on Insulating Substrates}

The ESD process can be easily used to perform film development by adjusting the liquid flow rate and the voltage applied to the nozzle, and it is less expensive for thin-film production relative to other chemical vapor, physical vapor, and plasma-spray deposition techniques that require high vacuum installations [27]. However, the major problem with the ESD process is the difficulty in obtaining any thin film onto every insulating substrate due to charge accumulation and the repelling of on-coming droplets during fabrication, as has been stated by Jaworeck [9]. In addition, in the present study, the peaks due to anatase were found in the XRD pattern of the FTOESD formed on the conductive substrate (Figure 3a). However, no peak from the QESD obtained by an identical electrospray treatment directly on the insulating quartz glass substrate could be observed in the XRD pattern (Figure 3b), under identical spray conditions in the case of FTOESD. This result is consistent with the fact that no level difference, which should be detected if a thin film existed on the quartz glass substrate, is found.

We therefore contrived the surface modification of the quartz glass substrate by forming the SWCNT ultra-thin film to form a precursor film on the insulating substrate via the ESD process. Consequently, a 90-nm-thick QCNTESD film could be obtained after heat-treating the precursor film formed by the ESD process (Figure 3b), similar to the FTOESD. Notably, the SWCNT precoated quartz glass substrate (QCNT) had a sheet resistance of $2 \times 10^{6} \Omega /$ sq., which is extremely high compared to the conductive FTO-precoated glass substrate, $45 \Omega /$ sq. Thus, it is revealed that the SWCNT ultra-thin film on the insulating substrate plays an important role in preventing the substrate from charge buildup during fabrication, even if the sheet resistance is not at a low level of a definite conductor.

\subsection{Homogeneous Coating of Titania Thin Films Via ESD Process}

The thin-film fabrication of titania from sol solutions on various substrates via the ESD process has been reported by several researchers $[17,28,29]$. In the case of the sol solution approach, the metal compounds used are generally unstable due to hydrolysis and polycondensation near room temperature, giving rise to a solution wherein polymers or colloidal particles involving metallic species are dispersed without precipitation. Further reaction connects the fine particles, thereby solidifying the sol into a wet gel, which still contains water and solvents [29].

Chen and coworkers reported that the dense morphology of titania using ethanolic precursor solutions could not be obtained via the ESD process because the organic compounds involved in the precursor solution could only be decomposed at high temperatures [27]. However, the FTOESD and QCNTESD could be facilely prepared using the molecular precursor solution involving organic compounds at $500^{\circ} \mathrm{C}$. It is important to note that they did not contain pinholes or cracks (Figure 2).

The surface roughness of the QCNTESD and QSPIN on the quartz glass substrate is negligibly small, although those of the FTOESD and FTOSPIN are larger than $10 \mathrm{~nm}$ (Table 1). It is acceptable that the originally large roughness of the precoated FTO film on the glass substrate caused the larger values of the latter two thin films. Because the molecular precursor solution contains organic compounds as the ligand and alkylammonium cation, it is evident that the formation of dense films depends on the principle of film formation. For the molecular precursor for titania thin film fabrication via the ESD process, the homogeneity of the coating solution involving an anionic metal complex with alkylammonium cations is useful for fabricating thin films with smooth surfaces. 


\subsection{Strong Adhesion of Titania Thin Films onto the Quartz Glass Substrate by Heat Treatment}

The AFM image of the QCNT before the formation of the titania precursor film via the ESD process shows the SWCNT networks on the quartz glass substrate with the rounded particles that disappear in the QCNTESD (Figures 1 and 2c). These results indicate that the SWCNT networks and rounded particles decompose during the heat treatment at $500{ }^{\circ} \mathrm{C}$ in air for $1 \mathrm{~h}$, and the rounded particles can thus be attributed to the organic dispersants being used in the commercially available SWCNT dispersed solutions.

No peak attributable to the SWCNT molecules could be observed in the Raman spectrum of the QCNTESD, similar to that of the QSPIN, wherein the titania thin film was fabricated directly on the quartz glass (Figure 6). Because the adhesion strength of the QCNTESD is comparable to that of the QSPIN, the titania thin films in this present study adhere strongly to the quartz glass substrate, independent of the coating process for forming the precursor film, after the heat treatment. It was thus clarified that the pre-modification of the substrate with SWCNT ultra-thin films did not prevent the resultant titania thin film from attaining strong adhesion onto the substrate.

\subsection{Co-Presence of Amorphous Phase with Anatase Crystals in Titania Thin Films Via the ESD Process}

It is evident from the XRD results that the titania thin films fabricated via the ESD process involve anatase crystals similar to those prepared via spin-coating (Figure 3). In addition, the crystallite size, which is an indicator of crystallization, of all the anatase phases is rather identical (Table 2). However, the XRD peak intensities of the titania thin films via the ESD process are apparently lower than those via the spin-coating process, even though the difference in film thickness between them is only $10 \%$. These results on XRD measurement suggest that the titania thin films produced via the ESD process involve a certain amount of amorphous phase in addition to the crystallized anatase portions.

The Raman spectra additionally show that the peak intensity of anatase found at 144 and 634 $\mathrm{cm}^{-1}$ of the thin films manufactured via the spin-coating process is higher than those fabricated via the ESD process, except for the FTOESD (Figure 6). The peak positions of anatase in the Raman spectra depend generally on the substrates, FTO-precoated glass, and quartz glass substrate [30]. In the case of the FTOESD, it is evident that the corresponding peak that overlaps accidentally with that of anatase is mainly due to the FTO-precoated glass substrate, as compared to the intensities of other peaks in the range of $100-700 \mathrm{~cm}^{-1}$. These Raman spectra results are consistent with the above-mentioned co-presence of an amorphous phase with anatase.

Furthermore, it is consistent with the notion that the co-presence of the amorphous phase that reduces the relative amount of anatase in the resultant titania thin films causes the lower PL emission intensity of the QCNTESD than that of the QSPIN (Figure 8).

It was thus revealed that the relative amount of crystallized anatase in the titania thin films depended on the coating process for forming precursor films, and that of the amorphous phase in the heat-treated titania thin films via the ESD process cannot be negligible. The precursor films of the FTOESD and QCNTESD, which were formed at high voltages exceeding $4 \mathrm{kV}$, had been applied to the molecular precursor solutions, and they involved the $\mathrm{Ti}^{4+}$ complex as the titania source. It is therefore easy to accept that the electrochemical reactions of $\mathrm{Ti}^{4+}$ species in the positively charged droplets occurred during the ESD process, although the resultant precursor films involved the original $\mathrm{Ti}^{4+}$ complex in the spin-coating process. Notably, the UV-Vis spectra of the precursor films via the ESD process are blue-shifted in the UV region, compared to those via spin-coating (Figure $7 \mathrm{~b}$ ). The blue shift is most likely due to the reductive elimination of the peroxo ligand originally involved in the precursor as an oxygen source for anatase to neutralize the positive charge of the droplets. This suggests that in the cases of the FTOESD and QCNTESD, the structure of the molecular precursor complex changed to further anatase formation during the subsequent heat treatment, and the amount of amorphous phase increased in the resultant thin films. The effects of this co-present amorphous phase in the titania thin films will be discussed in the subsequent sections. 


\subsection{Refractive Index and Optical Bandgap of Titania Thin Films Fabricated Via the ESD Process}

The co-presence of an amorphous phase with anatase will significantly affect the optical properties of the titania thin films, depending on the relative amount of each phase.

Very recently, the present authors reported extremely low refractive indices of 1.78-1.79 for amorphous titania thin films fabricated by UV irradiation at room temperature onto a spin-coated precursor film involving a $\mathrm{Ti}^{4+}$ complex of oxalato and peroxo ligands [31]. As summarized in Table 4, the refractive index of the QCNTESD is comparable to that of the previously reported amorphous titania, and lower than that of the QSPIN, which is comparable to the value of 2.10 reported for the spin-coated $\mathrm{TiO}_{2}$ thin film formed via the sol-gel method [32]. It is thus suggested that the refractive index of the present titania thin films apparently depends on the coating process for the precursor film formation, and the low refractive index of the thin films via ESD is mainly attributable to the amorphous phase co-present with anatase.

The optical bandgaps of the QCNTESD and QSPIN are rather identical to the reported value fabricated by ESD; it is larger than that of single-crystal anatase, $3.20 \mathrm{eV}[17,28]$. Generally, the large bandgaps are mainly attributed to the stress between the thin films and substrates in thin films [19]. The bandgap of the titania thin film produced via the ESD process, QCNTESD, is $0.04 \mathrm{eV}$ less than those prepared via the spin-coating process, which may be due to the relaxation of stress between the anatase crystals and substrates by the co-present amorphous phase.

It can also be assumed that the contribution of the amorphous components, structuring no regular lattice to function as a semiconductor, is quite inconsiderable. Notably, the transmittance of the QCNTESD does not reach $0 \%$ in the region of $200-300 \mathrm{~nm}$, indicating a certain level of transparency in this region (Figure $6 \mathrm{~b}$ ). This can be ascribed to the actual dilution of anatase fine crystals embedded in the titania thin film by the co-present amorphous phase with high transparency in the UV region.

\subsection{Hydrophilicity of Titania Thin Films Prepared Via the ESD Process}

In the present study, low water contact angles, such as $15^{\circ}$ and $14^{\circ}$, on the FTOESD and QCNTESD, which were both fabricated via the ESD process, can be observed before UV irradiation, although the corresponding angles on the two thin films obtained via spin-coating exceed $50^{\circ}$. In addition, all the present thin films have near-identical surface morphologies (Figure 2), whose differences generally affect the hydrophilic levels before UV irradiation [33,34].

Kuscer et al. reported the effect of the valence state of titanium ions on the hydrophilicity of ceramics in titanium-oxygen systems, such as $\mathrm{Ti}_{2} \mathrm{O}_{3} / \mathrm{Ti}_{3} \mathrm{O}_{5}$ crystal powders, and indicated that the presence of $\mathrm{Ti}^{3+}$ ions introduced at the surface could contribute to a significant decrease in the water contact angle of $18^{\circ}$ even before UV irradiation [34]. Therefore, the high hydrophilicity observed in the titania thin films fabricated via the ESD process before UV irradiation can be mainly due to the co-presence of $\mathrm{Ti}^{3+}$ ions, which is established by the present XPS analyses. The decisive difference from the $\mathrm{Ti}_{2} \mathrm{O}_{3} / \mathrm{Ti}_{3} \mathrm{O}_{5}$ crystal system, whose color is black owing to the typical semiconductor, is the colorless property of the present titania thin films. This suggests that the $\mathrm{Ti}^{3+}$ ions, which can exhibit effective hydrophilicity, exist locally in the amorphous phase of the thin films prepared via the ESD process, prior to being an analogous crystal structure, such as $\mathrm{Ti}_{2} \mathrm{O}_{3}$. The XPS results also suggest that the $\mathrm{Ti}^{3+}$ ions accompanied by the oxygen deficiency presented in the anatase lattice do not demonstrate hydrophilic properties before UV light irradiation (Tables 3 and 5).

By the UV irradiation of the thin films in this study, an extreme decrease in water contact angles was evident in every case. In particular, after the UV irradiation of the FTOESD and QCNTESD, the super-hydrophilicity, indicating an angle of approximately zero, was demonstrated. This photo-induced hydrophilicity and super-hydrophilicity may be due to the synergetic effect of co-present $\mathrm{Ti}^{3+}$ ions locally in the amorphous phase and the photo-excitation of crystallized anatase. 


\section{Conclusions}

A useful procedure to fabricate titania thin films on insulating quartz glass substrates via the ESD process, which was used to form the precursor film, was demonstrated for the first time. The molecular precursor solution was successfully electrosprayed onto the surface-modified substrate with an SWCNT ultra-thin film. The heat treatment of the precursor film at $500{ }^{\circ} \mathrm{C}$ in air was useful for fabricating a titania thin film with a smooth surface and strong adhesion on the substrate, as well as to remove the precoated SWCNT ultra-thin film.

The use of an identical molecular precursor solution evidently demonstrated the different properties of titania thin films fabricated via ESD and spin coating processes. The relative amounts of crystallized anatase after the precursor films, which are heat-treated at $500{ }^{\circ} \mathrm{C}$ for $1 \mathrm{~h}$, are the major differences shown by their XRD, Raman, and photoluminescence spectra. A part of the Ti species in the precursor film fabricated through the ESD process did not form crystallized anatase even after the heat treatment and remained in the amorphous phase of the resultant titania thin films. The amorphous phase of the titania thin films prepared via the ESD process affects the optical characteristics, for example, low refractive index, high optical bandgap, and transparency in the UV region compared to those manufactured via spin-coating. The co-present $\mathrm{Ti}^{3+}$ ions, which have no ability to structure anatase directly but can offer hydrophilicity, remain in the amorphous phase of the titania thin films fabricated via the ESD process. Thus, a useful feature of the ESD process was established in this study.

Author Contributions: Conceptualization, H.N., Y.K., T.T., T.O. and M.S.; Methodology, H.N., Y.K., T.T., T.O. and M.S.; Investigation, N.H.S., Y.S., R.O., H.N., Y.K., T.T., T.O. and M.S.; Writing-Original Draft Preparation, N.H.S. and H.N.; Writing-Review and Editing, Y.K., T.T., T.O., H.N. and M.S.; Supervision, H.N. and M.S. All authors have read and agreed to the published version of the manuscript.

Funding: This work was supported by Japan Society for the Promotion of Science (JSPS) KAKENHI Grant Number JP20K05270, and the Japan Science and Technology Agency (JST)-Mirai Program, Grant Number JPMJMI18DA. This study was also financially supported by the International Research Project of Kogakuin University in collaboration with the National University of Singapore.

Conflicts of Interest: The authors declare no conflict of interest.

\section{References}

1. Syafiq, A.; Vengadaesvaran, B.; Pandey, A.K.; Nasrudin, A.R. Superhydrophilic smart coating for self-cleaning application on glass substrate. J. Nanomater. 2018, 2018, 6412601. [CrossRef]

2. Ganesh, V.A.; Raut, H.K.; Nair, A.S.; Ramakrishna, S. A review on self-cleaning coatings. J. Mater. Chem. 2011, 21, 16304-16322. [CrossRef]

3. Mills, A.; Crow, M. A study of factors that change the wettability of titania films. Int. J. Photoenergy 2008, 470670. [CrossRef]

4. Nundy, S.; Ghosh, A.; Mallick, T.K. Hydrophilic and Superhydrophilic Self-Cleaning Coatings by Morphologically Varying ZnO Microstructures for Photovoltaic and Glazing Applications. ACS Omega 2020, 5, 1033-1039. [CrossRef] [PubMed]

5. Rudakova, A.V.; Emeline, A.V.; Bulanin, K.M.; Aida, V.; Emeline, A.V.; Bulanin, K.M.; Chistyakova, L.V.; Maevskaya, M.V.; Bahnemann, D.W. Self-cleaning properties of zirconium dioxide thin films. J. Photochem. Photobiol. A Chem. 2018, 367, 397-405. [CrossRef]

6. Bico, J.; Thiele, U.; Quéré, D. Wetting of textured surfaces. Colloids Surf. A Physicochem. Eng. Asp. 2002, 206, 41-46. [CrossRef]

7. Cebeci, F.C.; Wu, Z.; Zhai, L.; Cohen, R.E.; Rubnere, M.F. Nanoporosity-driven superhydrophilicity: A means to create multifunctional antifogging coatings. Langmuir 2006, 22, 2856-2862. [CrossRef] [PubMed]

8. Jaworek, A.; Sobczyk, A.T. Electrospraying route to nanotechnology: An overview. J. Electrost. 2008, 66, 197-219. [CrossRef]

9. Jaworek, A. Electrospray droplet sources for thin film deposition. J. Mater. Sci. 2007, 42, 266-297. [CrossRef]

10. Nagai, H.; Sato, M. Advanced Coating Materials; John Wiley \& Sons, Inc.: Hoboken, NJ, USA, 2018; pp. 1-27. [CrossRef] 
11. Nagai, H.; Sato, M. Heat Treatment in Molecular Precursor Method for Fabricating Metal Oxide Thin Films. Heat Treat. Conv. Nov. Appl. 2012. [CrossRef]

12. Sato, M.; Hara, H. A water-resistant precursor in a wet process for $\mathrm{TiO}_{2}$ thin film formation. J. Mater. Chem. 1996, 6, 1767-1770. [CrossRef]

13. Nagai, H.; Aoyama, S.; Hara, H.; Mochizuki, C.; Takano, I.; Baba, N.; Sato, M. Rutile thin film responsive to visible light and with high UV light sensitivity. J. Mater. Sci. 2009, 44, 861-868. [CrossRef]

14. Nagai, H.; Hasegawa, M.; Hara, H.; Mochizuki, C.; Takano, I.; Sato, M. An important factor for controlling the photoreactivity of titania: O-deficiency of anatase thin films. J. Mater. Sci. 2008, 43, 6902-6911. [CrossRef]

15. Unwiset, P.; Chanapattharapol, K.C.; Kidkhunthod, P.; Poo-arporn, Y.; Ohtani, B. Catalytic activities of titania-supported nickel for carbon-dioxide methanation. Chem. Eng. Sci. 2020, 228, 115955. [CrossRef]

16. Suwazono, Y.; Nagai, H.; Sato, M. Photovoltaic Lithium-ion Battery with Layer-Structured $\mathrm{Li}_{2} \mathrm{Mn}^{\mathrm{III}}{ }_{0.2} \mathrm{Mn}^{\mathrm{IV}}{ }_{0.8} \mathrm{O}_{2.9}$ Thin Film Chemically Fabricated for Cathodic Active Material. Energies 2020, 13, 1486. [CrossRef]

17. Choi, K.H.; Duraisamy, N.; Muhammad, N.M.; Kim, I.; Choi, H.; Jo, J. Structural and optical properties of electrohydrodynamically atomized $\mathrm{TiO}_{2}$ nanostructured thin films. Appl. Phys. A Mater. Sci. Process. 2012, 107, 715-722. [CrossRef]

18. Sta, I.; Jlassi, M.; Hajji, M.; Boujmil, M.F.; Jerbi, R.; Kandyla, M.; Kompitsas, M.; Ezzaouia, H. Structural and optical properties of $\mathrm{TiO}_{2}$ thin films prepared by spin coating. J. Sol-Gel Sci. Technol. 2014, 72, 421-427. [CrossRef]

19. Ghosh, G. Dispersion-equation coefficients for the refractive index and birefringence of calcite and quartz crystals. Opt. Commun. 1999, 163, 95-102. [CrossRef]

20. Biesinger, M.C.; Lau, L.W.M.; Gerson, A.R.; Smart, R.S.C. Resolving surface chemical states in XPS analysis of first row transition metals, oxides and hydroxides: Sc, Ti, V, Cu and Zn. Appl. Surf. Sci. 2010, 257, 887-898. [CrossRef]

21. Morales, E.R.; Mathews, N.R.; Reyes-Coronado, D.; Magaña, C.R.; Acosta, D.R.; Alonso-Nunez, G.; Martinez, O.S.; Mathew, X. Physical properties of the $\mathrm{CNT}$ : $\mathrm{TiO}_{2}$ thin films prepared by sol-gel dip coating. Sol. Energy 2012, 86, 1037-1044. [CrossRef]

22. Hennrich, F.; Krupke, R.; Lebedkin, S.; Arnold, K.; Fischer, R.; Resasco, D.E.; Kappes, M.M. Raman spectroscopy of individual single-walled carbon nanotubes from various sources. J. Phys. Chem. B 2005, 109, 10567-10573. [CrossRef] [PubMed]

23. Gallart, M.; Cottineau, T.; Hönerlage, B.; Keller, V.; Keller, N.; Gilliot, P. Temperature dependent photoluminescence of anatase and rutile $\mathrm{TiO}_{2}$ single crystals: Polaron and self-trapped exciton formation. $J$. Appl. Phys. 2018, 124. [CrossRef]

24. Pallotti, D.K.; Passoni, L.; Maddalena, P.; Di Fonzo, F.; Lettieri, S. Photoluminescence Mechanisms in Anatase and Rutile $\mathrm{TiO}_{2}$. J. Phys. Chem. C 2017, 121, 9011-9021. [CrossRef]

25. He, J.; Behera, R.K.; Finnis, M.W.; Li, X.; Dickey, E.C.; Phillpot, S.R.; Sinnott, S.B. Prediction of high-temperature point defect formation in $\mathrm{TiO}_{2}$ from combined ab initio and thermodynamic calculations. Acta Mater. 2007, 55, 4325-4337. [CrossRef]

26. Yang, K.H.; Chen, T.Y.; Ho, N.J.; Yang, L.H. In-gap states in wide-band-gap $\mathrm{SrTiO}_{3}$ analyzed by cathodoluminescence. J. Am. Ceram. Soc. 2011, 94, 1811-1816. [CrossRef]

27. Chen, C.H.; Kelder, E.M.; Schoonman, J. Electrostatic sol-spray deposition (ESSD) and characterisation of nanostructured $\mathrm{TiO}_{2}$ thin films. Thin Solid Films 1999, 342, 35-41. [CrossRef]

28. Mahalingam, S.; Edirisinghe, M.J. Characteristics of electrohydrodynamically prepared titanium dioxide films. Appl. Phys. A Mater. Sci. Process. 2007, 89, 987-993. [CrossRef]

29. Jeffrey, C.B.; Scherer, G.W. Sol-Gel Science; Academic Press: Cambridge, MA, USA, 1990. [CrossRef]

30. Alhomoudi, I.A.; Newaz, G. Residual stresses and Raman shift relation in anatase $\mathrm{TiO}_{2}$ thin film. Thin Solid Films 2009, 517, 4372-4378. [CrossRef]

31. Wu, H.J.; Tanabe, K.; Nagai, H.; Sato, M. Photo-Induced Super-hydrophilic Thin Films on Quartz Glass by UV Irradiation of Precursor Films Involving a Ti(IV) Complex at Room Temperature. Materials 2019, 12, 348. [CrossRef]

32. Bittencourt, C.; Rutar, M.; Umek, P.; Mrzel, A.; Vozel, K.; Arčon, D.; Henzler, K.; Krüger, P.; Guttmann, P. Molecular nitrogen in $\mathrm{N}$-doped $\mathrm{TiO}_{2}$ nanoribbons. RSC Adv. 2015, 5, 23350-23356. [CrossRef] 
33. Yu, J.C.; Yu, J.; Hung, Y.T.; Zhang, L. Effect of surface microstructure on the photoinduced hydrophilicity of porous $\mathrm{TiO}_{2}$ thin films. J. Mater. Chem. 2002, 12, 81-85. [CrossRef]

34. Kuscer, D.; Kovač, J.; Kosec, M.; Andriesen, R. The effect of the valence state of titanium ions on the hydrophilicity of ceramics in the titanium-oxygen system. J. Eur. Ceram. Soc. 2008, 28, 577-584. [CrossRef]

Publisher's Note: MDPI stays neutral with regard to jurisdictional claims in published maps and institutional affiliations.

(C) 2020 by the authors. Licensee MDPI, Basel, Switzerland. This article is an open access article distributed under the terms and conditions of the Creative Commons Attribution (CC BY) license (http://creativecommons.org/licenses/by/4.0/). 